\title{
BILAYER AGENT-BASED MODEL OF SOCIAL BEHAVIOR: HOW TEMPERAMENT INFLUENCE ON TEAM PERFORMANCE
}

\author{
Daria Barteneva \\ Luís Paulo Reis \\ Faculty of Engineering - University of Porto \\ Rua Dr. Roberto Frias, s/n 4200-465 Porto, Portugal \\ E-mails: daria.barteneva@gmail.com; lpreis@fe.up.pt
}

\author{
Nuno Lau \\ Department of Electronics and Telecommunications of the \\ Aveiro University, phone: +351 34 370500; fax: +35134 \\ 370545, Portugal \\ E-mail: lau@det.ua..pt
}

\author{
KEYWORDS \\ Multi-Agent Simulation, Emotional Behaviors, Mind \\ Programming.
}

\begin{abstract}
This paper presents the evaluation of computational mind model based on temperamental decision algorithms with emotional behaviors. Our computational model of emotion is inspired on appraisal theory and on superior nervous system characteristics. We define the model for temperamental agent with emotions. In this paper we prove that teams of the agents with different temperaments have different performances in the same simulation scenario. The result shows that strategies based on temperamental decision mechanism strongly influence system performance and there are evident dependencies between emotional states of agents and their temperamental type, as well as dependencies between the team performance and team configuration, and this enables us to conclude that modular approach to emotional programming based on temperamental theory is a good choice to develop computational mind models for emotional behavioral Multi-Agent systems.
\end{abstract}

\section{INTRODUCTION}

Emotions are part of our lifes. They help us focus attention, remember, prioritize, understand and communicate. The possibility of computation of emotions is the exciting and interesting task. The emotions influence decision-making processes, socialization, communication, learning and many other important issues of our life.

Why program emotions?

Implementation of emotions in an artificial organism is an important step for different areas of intervention, since academical inquiry [1-10], education [13-15], communication $[11,16]$, entertainment and others [12, $17-19,29,30]$. Researchers who focused on the functions of emotion for computational models trying to describe some of behavioral responses to reinforcing signals, communications which transmit the internal states or social bonding between individuals, which could increase fitness in the context of evolution. Among some models of emotions that are described through the computational process exists different approaches to the proper concept of emotion. Each model results of the definition that is given to the emotional process. Since analysis of needs/satisfactions of the human being [24, 25], passing through the analysis of characteristics of the superior nervous system [26, 28], physiological changes [23, 31], neurobiological processes [27], appraisal mechanism and analysis of the psychology of individual personality $[20,21]$.

\section{Emotions and temperament}

For our project we define emotions as a set of external and internal responses which depends on the set of rules based on agent beliefs, desires and intentions. To proceed with development of our computational model of emotional we need to use some kind of quantitative measure to evaluate emotional state. But what is "Emotional state"? Interesting definition was given by Mehrabian [21] for this concept. He defined it as transitory conditions of the organism - conditions that can vary substantially, and even rapidly, over the course of a day. He also defined "emotional traits" (i.e. Temperament) as conditions that are stable over periods of the year or even a lifetime. As described in Pavlov's theory [28], all human and animal behaviors are coordinated by the Central Nervous System (CNS). Therefore we can't study emotional agents without considering the particularities of the CNS and, consequently, the particularities of temperamental theory.

The classical definition for "Temperament" follows: it is a specific feature of Man, which determines the dynamics of his mental activity and behaviour. Two basic indexes of the dynamics of mental processes and behaviours are distinguishable at present: activity and emotionality. In this paper we will analyze an emotional model for the agents with temperament. We will use a complex approach to emotion/temperament concepts: based on physiological (CNS) characteristics and on psychological characteristics of the agents. 
The scientific explanation of temperaments was given by Ivan Pavlov's study about the types of higher nervous activity. Pavlov discovered three properties of the processes of excitation and braking [28, 37]:

1. the force of the processes of excitation and braking;

2. the steadiness of the processes of excitation and braking;

3. the mobility of the processes of excitation and braking.

We use Pavlov's theory as the basis to define the model of temperament. Pavlov correlated the types of nervous systems with the psychological types of temperaments isolated with it and revealed their complete similarity. Thus, temperament is a manifestation of the type of nervous system into the activity, the behavior of man. As a result the relationship of the types of nervous system and temperaments appears as follows:

4. Strong, balanced, mobile type - sanguine temperament;

5. Strong, balanced, inert type - phlegmatic temperament;

6. Strong, unbalanced, with the predominance of excitation - choleric temperament;

7. Weak type - melancholic temperament.

Analysis of emotional states leads to the conclusion that human emotions such as anger, fear, depression, elation, etc. are discrete and we need to define some kind of values to have a basic framework to describe each emotional state using the same scale. After studying the appraisal theory we find the Mehrabian model [20, 21] more suitable for computational needs since it defines three dimensions to describe each emotional state and provides an extensive list of emotional labels for points in the Pleasure, Arousal and Dominance (PAD) space and gives an impression of the emotional meaning of combinations of Pleasure, Arousal and Dominance (PAD).

Three dimensions of the PAD temperamental model define a three-dimensional space where individuals are represented as points, personality types are represented as regions and personality scales are represented as straight lines passing through the intersection point of the three axes. Mehrabian uses $+\mathrm{P},+\mathrm{A}$ and $+\mathrm{D}$ to refer pleasant, arousable and dominant temperament. Respectively, and by using -P, $-\mathrm{A}$ and $-\mathrm{D}$ to refer unpleasant, unarousable and submissive temperament, respectively. Since most personality scales load on two or more of the PAD temperament dimensions, Mehrabian defines them using the four diagonals in PAD space as follows:

$$
\begin{aligned}
& \text { Exuberant }(+\mathrm{P}+\mathrm{A}+\mathrm{D}) \text { vs. Bored }(-\mathrm{P}-\mathrm{A}-\mathrm{D}) \\
& \text { Dependent }(+\mathrm{P}+\mathrm{A}-\mathrm{D}) \text { vs. Disdainful }(-\mathrm{P}-\mathrm{A}+\mathrm{D}) \\
& \text { Relaxed }(+\mathrm{P}-\mathrm{A}+\mathrm{D}) \text { vs. Anxious }(-\mathrm{P}+\mathrm{A}-\mathrm{D}) \\
& \text { Docile }(+\mathrm{P}-\mathrm{A}-\mathrm{D}) \text { vs. Hostile }(-\mathrm{P}+\mathrm{A}+\mathrm{D})
\end{aligned}
$$

To create a more flexible and efficient emotion-based behavior system, the appraisal model is implemented in mixture with Pavlov's temperamental theory [28] which studies the basic reasons for different temperamental behaviors and Eysenck's [26] neurophysiological interpretation of the basic values of temperament.

\section{Paper Structure}

The paper is organized as follows. Section 2 summarize the model characteristics we have implemented to perform the tests. Section 3 describes the evaluations experiences performed in different scenarios. Section 4 presents the conclusion and future work.

\section{TEMPERAMENTAL AND EMOTIONAL MODEL}

We choose the approach to emotional programming through the implementation of artificial personalities and the integration of the emotional model based on the appraisal theory. The innovation of our approach consists in the duality of our emotional character: it processes the information and gives the output using two different engines, physiological and psychological. In our model the temperament of the agent is defined as the configuration of his mechanical engines and the personality functions which simulates his psyche as the decision mechanism. The emotional response of the agent possesses a dual mechanism: it is physiological (such as motor and sensor force, face expression, mobility) and psychological (such as a vector which defines his internal emotional state).

We also need to emphasize the difference between the agent's temperamental state and agent's emotional state. Temperament, as we already defined, is the steady characteristics of the agent which is "innate" and do not suffer alterations during the agent's life. On the other side, the emotional state of the agent is the dynamic set of values which depends on the external influences, and on the agent's temperament.

And emotions have a role of heuristic relating events to goals, needs, desires, beliefs of an agent and evaluate their personal relevance and help decision-making.

So, for instance, two agents with different temperaments and the same emotional states on some temporal period, which receive the same external input will have different responses on both, the physiological and the psychological mechanism. We also define different sets of needs and motivations for each temperamental type by the influence of the agent's performance and stimuli on the team work. It is not the goal of this paper to describe all temperamental needs and the detailed structure of the temperamental decision mechanism. This modular, but complementary approach, is the core of the innovation of our emotional system and our aspiration of its usability. 


\section{Bilayer architecture}

We assume bilayer architecture for our emotional model. One layer is physiological and describes the superior Nervous system from the Pavlov perspective. The other layer is psychological and works with the appraisal model created by Mehrabian.

\begin{tabular}{|c|c|c|}
\hline Temperament & Propertie \\
\hline $\begin{array}{c}\text { Psychological } \\
\text { layer }\end{array}$ & Affected \\
\hline $\begin{array}{c}\text { Physiological } \\
\text { layer }\end{array}$ \\
\hline $\begin{array}{c}\text { Arousal } \\
\text { Dominance }\end{array}$ \\
\hline $\begin{array}{c}\text { Force } \\
\text { Steadiness }\end{array}$ \\
\hline
\end{tabular}

Figure 1: Temperamental Architecture

\section{Physiological Layer}

The physiological layer of our model have a role of the simplified Central Nervous System as it was described by the Pavlov. In his theory all temperamental characteristics are based on force, mobility and steadiness of the processes of excitation and breaking. We decided to describe this as physiological characteristics of the agents. This layer was well described in our previous work [39].

In our multi-agent system the force of excitation and braking processes is represented by the force of the motor and reach of the sensors.

The mobility of the agent is represented by its "persistence" to reach the goal and avoid negative emotions. For instance if some agent is "comfortable" in some place, and his mobility is low, he will not look to move to search other places. He will slow his motors and just stay in the same place until his emotional state changes and forces him to move quickly. At the same time, one agent who has a high mobility will search new places and new directories even if he is comfortable enough in some temporal phase.

The steadiness of the agent is the velocity of his emotional state variation. For example, more balanced agents have a slow variation of emotional state. For this we introduce the variable called Anxiety which is used to increase or decrease the Pleasure variable. The value of Anxiety depends on the temperament of the agent.

\section{Psychological Layer}

Psychological layer of our model is the evaluation mechanism which works in order to analyze all external events received by the agent through his different sensors (obstacle, vision, etc...) and actualize the internal emotional state of the agent.

Our approach does not prescribe a specific set of appraisal dimensions. We have chosen the Pleasure, Arousal, Dominance (PAD) personality-trait and emotional-state scales by Albert Mehrabian [21] because these dimensions are generally not considered to be appraisal dimensions. He argues that any emotion can be expressed in terms of values on these three dimensions, and provides extensive evidence for this claim [20]. This makes his three dimensions suitable for a computational approach. Mehrabian also provides an extensive list of emotional labels for points in the PAD space [21] and gives an impression of the emotional meaning of the combinations of Pleasure, Arousal and Dominance. The emotional-state of an agent can thus be understood as a continuously moving point in an ndimensional space of appraisal dimensions.

To perform emotional evaluation of the events received by the agents we have defined appraisal banks which relate the events with the Pleasure, Arousal and Dominance values. We have defined three appraisal banks, one related to survival, second related to the goals and the last one related to the specific temperamental needs of the agent. To evaluate the weight of the event received by the agent in PAD values we define Pleasure as the conductance of the goal. For instance if the agent sees the goal and no obstacle is present his pleasure is high, while if he sees a threat or looses the goal this is highly unpleasant. Arousal is the amount of attention each event needs, for instance to avoid threats the attention of the agent is needed and lose it needs no attention. Dominance is a measure that defines the amount of freedom of the agent. For example, if the agent sees a lot of obstacles then his dominance decrease. According to Mehrabian [21] arousal is highly correlated with activity and alertness so changing the Arousal we can control the Mobility of the agent.

To perform emotional evaluation of the events received by the agent we defined appraisal banks which relate each event with its PAD values. We defined three appraisal banks related to survival, points and goal.

Appraisal-results are integrated using following formula,

$$
E_{t+1}=E_{t}+\sum_{i=0}^{n} \Delta P A D_{t i}
$$

where $E_{t}$ is the emotional-state at time $t, E_{t+1}$ is the new emotional-state, $\mathrm{n}$ is the number of appraisal banks and $\Delta \mathrm{PAD}_{\mathrm{ti}}$ the appraisal-result vector of bank $i$ at time $t$.

\section{EVALUATION}

A simulation environment based on a Cyber-Mouse [34, 35] competition simulator was used to test and evaluate the strategies used on the work. A set of robotic experiments was conducted in order to test the performance of the system.

Cyber-Mouse is a modality included in the MicroMouse competition organized by Aveiro University (Portugal). This modality is supported by a software environment, which simulates both robots and a labyrinth. All virtual robots have the same kind of body. 
It is composed of a cylindrical shape, equipped with sensors, actuators, and command buttons. The simulator estimates sensor measures which are sent to the agents. Reversely, receives and apply actuating orders coming from agents.

Agents are given the following challenge: starting from their position in starting grid they must visit the target area and then return the their starting point. Score depends on fulfillment of challenge goals and on penalties suffered. Technically speaking, the task of the robots is to go from their starting position to the target area signalled by an infra-red light emitting beacon, and then return to their starting position. The final score depends on the distance from the starting to the ending point, on the time taken to return and on possible penalties due mainly to collisions with walls and other robots.

We make the evaluations using teams with 9 agents. We define different teams of the temperamental agents to perform the evaluation of team performance. To test our model we analyze homogeneous teams of Choleric, Phlegmatic, Sanguine and Melancholic agents and heterogeneous teams with different temperamental agents in the same team.

To perform our tests, we evaluated the agent's performance on reaching the goal and the appraisal values modifications during the simulation time. We performed the evaluation of an entire team of the agents, in order to compare their performance with other teams of agents. During these evaluations we tried to analyze the difference between distinct temperamental teams and compare them in general terms (PAD scale and emotion valence), as well as their performance on reaching the goal.

We perform the evaluation by three different simulation scenarios:

First scenario has few obstacles (walls) and a small arena. These conditions enable fast detection of the beacon to the agents, but force the interaction between agents across the simulation arena.

Second scenario has more obstacles (walls) and a larger arena. In this scenario the goal is very difficult to accomplish and the agents have enough space for team interaction (grouping or isolation).

Third scenario has a lot of obstacles (walls) and a small arena. In this scenario the goal is very difficult to accomplish, and the agents have fewer space for team interaction (grouping or isolation).

We analyze our agent's performance on these three simulation scenarios and try to discover the advantages and disadvantages of using temperamental agents with this kind of simulation. We perform 10 interactions for each team/simulation scenario. The PAD values are presented in $[-10,10]$ interval instead of $[-1,1]$.

Note: To understand the evaluation results Table 3, please see the Table 1 and the Table 2 which contains the detailed description of each header and abbreviation of the Table 3.

Table 1: Scenario Descriptions

\begin{tabular}{|l|l|} 
Eval & Description \\
\hline 1C & Choleric Team in the Small Simple Scenario \\
\hline 2C & Choleric Team in the Large Complex Scenario \\
\hline 3C & Choleric Team in the Small Complex Scenario \\
\hline 1S & Sanguine Team in the Small Simple Scenario \\
\hline 2S & Sanguine Team in the Large Complex Scenario \\
\hline 3S & Sanguine Team in the Small Complex Scenario \\
\hline 1M & Melancholic Team in the Small Simple Scenario \\
\hline 2M & Melancholic Team in the Large Complex Scenario \\
\hline 3M & Melancholic Team in the Small Complex Scenario \\
\hline 1P & Phlegmatic Team in the Small Simple Scenario \\
\hline 2P & Phlegmatic Team in the Large Complex Scenario \\
\hline 3P & Phlegmatic Team in the Small Complex Scenario \\
\hline 1H & Heterogeneous Team in the Small Simple Scenario \\
\hline 2H & Heterogeneous Team in the Large Complex Scenario \\
\hline 3H & Heterogeneous Team in the Small Complex Scenario \\
\hline & \\
\hline
\end{tabular}

Table 2: Labels for Tables $3 \mathrm{a}$ and $3 \mathrm{~b}$

\begin{tabular}{|l|l|}
\hline Title & Description \\
\hline Eval. & The type of evaluation performed. We will use the index \\
\hline$\%$ & Percentage of the agents which has accomplished the goal \\
\hline B.T. & Best Time of the team across the all simulations \\
\hline A.T. & Average Time of the agents team \\
\hline Motor & Average value of the motor strength \\
\hline Sensor & Average value of the sensor strength \\
\hline Anx. & Average value of the Anxiety (or Emotional Stability) \\
\hline P & Average Pleasure of the team \\
\hline A & Average Arousal of the team \\
\hline D & Average Dominance of the team \\
\hline E.S. & Average Emotional State of the team \\
\hline
\end{tabular}

The evaluation results follows:

\begin{tabular}{|l|l|l|l|l|l|l|}
\multicolumn{7}{|c|}{ Table 3a: Evaluation Results } \\
Eval. & $\%$ & B.T. & A.T. & Motor & Sensor & Anx. \\
\hline 1C & 26,00 & 31,60 & 155,18 & 11,11 & 10,22 & 4,81 \\
\hline 2C & 16,00 & 67,80 & 165,43 & 11,22 & 10,44 & 5,89 \\
\hline 3C & 7,40 & 136,20 & 172,22 & 11,00 & 10,00 & 6,00 \\
\hline 1S & 33,00 & 19,00 & 147,95 & 10,89 & 10,30 & 20,04 \\
\hline 2S & 5,00 & 172,50 & 179,72 & 10,85 & 10,30 & 20,74 \\
\hline
\end{tabular}




\begin{tabular}{|l|l|l|l|l|l|l|}
$3 \mathrm{~S}$ & 0,10 & 172,80 & 179,83 & 11,00 & 10,00 & 20,00 \\
\hline $1 \mathrm{M}$ & 11,11 & 110,80 & 173,53 & 6,00 & 5,00 & 8,00 \\
\hline $2 \mathrm{M}$ & 0,11 & 137,90 & 163,66 & 6,00 & 5,00 & 8,00 \\
\hline $3 \mathrm{M}$ & 0,00 & 180,00 & 180,00 & 6,00 & 5,00 & 8,00 \\
\hline $1 \mathrm{P}$ & 33,00 & 96,80 & 161,70 & 11,00 & 10,00 & 22,00 \\
\hline $2 \mathrm{P}$ & 22,00 & 148,00 & 174,20 & 11,00 & 10,00 & 22,00 \\
\hline $3 \mathrm{P}$ & 11,00 & 169,70 & 178,86 & 11,00 & 10,00 & 22,00 \\
\hline $1 \mathrm{H}$ & 70,37 & 17,60 & 124,57 & 9,89 & 8,89 & 14,67 \\
\hline $2 \mathrm{H}$ & 22,00 & 138,20 & 174,16 & 9,89 & 8,89 & 14,67 \\
\hline $3 \mathrm{H}$ & 3,70 & 173,90 & 179,32 & 9,89 & 8,89 & 14,67 \\
\hline
\end{tabular}

Table 3b: Evaluation Results

\begin{tabular}{|l|l|l|l|l|}
\hline Eval. & P & A & D & E.S. \\
\hline 1C & 1,53 & $-0,41$ & 1,53 & 0,70 \\
\hline 2C & $-1,29$ & 2,16 & $-1,29$ & $-63,14$ \\
\hline $3 \mathrm{C}$ & 0,06 & 0,14 & 0,06 & $-34,91$ \\
\hline $1 \mathrm{~S}$ & $-0,48$ & 1,61 & $-0,48$ & $-23,36$ \\
\hline $2 \mathrm{~S}$ & 0,22 & 0,38 & 0,22 & $-79,37$ \\
\hline $3 \mathrm{~S}$ & $-0,43$ & 0,53 & $-0,42$ & $-29,36$ \\
\hline $1 \mathrm{M}$ & 0,13 & 1,14 & 0,13 & $-40,19$ \\
\hline $2 \mathrm{M}$ & 0,03 & 0,57 & 0,03 & $-69,94$ \\
\hline $3 \mathrm{M}$ & 1,45 & $-0,86$ & 1,45 & $-59,98$ \\
\hline $1 \mathrm{P}$ & $-0,54$ & 1,77 & $-0,54$ & $-43,34$ \\
\hline $2 \mathrm{P}$ & $-1,39$ & 2,11 & $-1,39$ & $-61,17$ \\
\hline $3 \mathrm{P}$ & $-1,05$ & 1,65 & $-1,05$ & $-45,55$ \\
\hline $1 \mathrm{H}$ & 1,16 & $-0,06$ & 1,16 & 7,68 \\
\hline $2 \mathrm{H}$ & 0,04 & 0,7 & 0,04 & $-75,13$ \\
\hline $3 \mathrm{H}$ & 0,26 & 0,04 & 0,26 & $-35,00$ \\
\hline
\end{tabular}

On Figure 2 we can observe the dependencies between Team Performance and Emotional State of the agents. The superior line represents the Percentage of the agents which has accomplished the goal and the lower line presents the Average Emotional State of the agents during the simulation. In our architecture the performance of the agents doesn't depend on appraisal mechanism which only controls the psychological layer of the agent and only influences his PAD values and the emotional state. The agents performance only depends on temperamental (physiological) configuration of the agent (motors, sensors, anxiety, etc..) and his decision layer based on temperamental characteristics. So, we can see that the temperamental decision mechanism clearly influence the emotional state of the agent during the simulation.

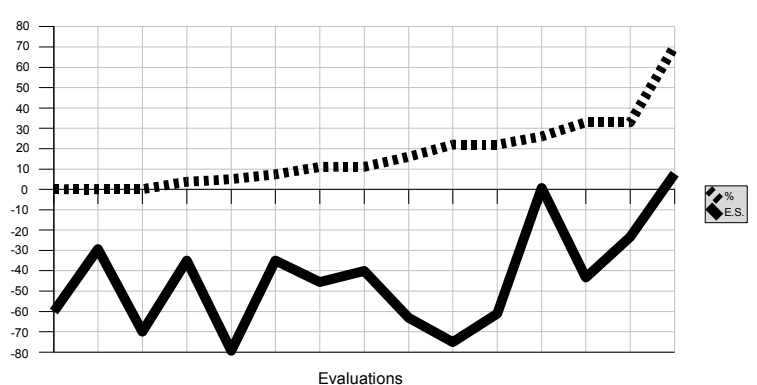

Figure 2: Team performance vs Appraisal Emotional State

To explain the nature of this influence we think that the implementation of the Pavlov's temperamental theory results in agents executing different grouping activities to satisfy their temperamental needs, so, this could influence the PAD values and consequently the Emotional State of the agent. Also we can analyze the influence of the system goals on the Emotional State of the agent (from the Appraisal Bank), and the decision temperamental mechanism works in order to accomplish some of these goals (avoid the walls, reach the beacon, etc). So, even having no trivial dependence between the implementation of these two layers, there are similar goals which are defined and this could explain the dependence between the agent performance and his Emotional State.

Figure 3 shows values of the Team Performance and the Emotional State for each simulation scenario. The superior line represents the Percentage of the agents which has accomplished the goal and the lower line presents the Average Emotional State of the agents during the simulation. Therefore the better performance corresponds to the first simulation scenario for all teams except the Melancholic Homogeneous team, while Phlegmatic homogeneous and Heterogeneous teams have good performance in the other scenarios. Agents Emotional state is good in the first and third scenarios, specially for the Choleric and Heterogeneous team, in contrast Melancholic and Phlegmatic teams Emotional State isn't so good.

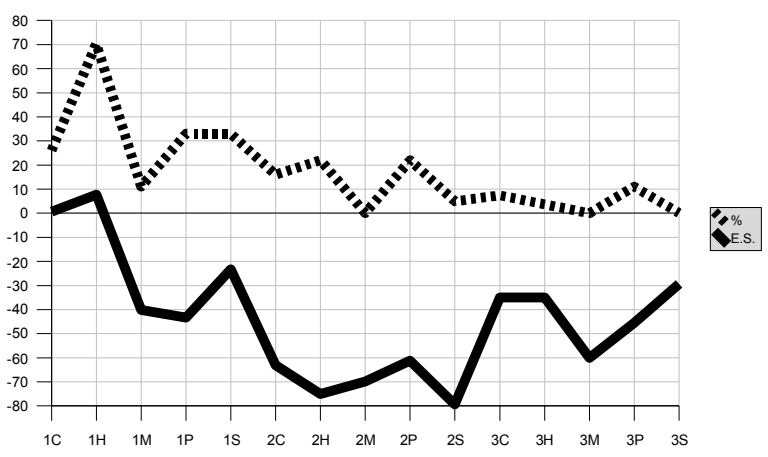

Figure 3: Team Performance and Emotional State by different scenarios 


\section{CONCLUSIONS AND FUTURE WORK}

A main goal of this project was to develop and test a new model of a computational emotional mind using two different temperamental theories. For tackling this domain, we initially study the basics of psychology and different approaches to evaluate emotional life of personality from temperamental perspective. As a rule, the theories of emotions can not say too much about the role of emotions in the development of personality and about their influence on thought and action. The majority of the researchers of emotions are connected only with one of the components of the emotional process. Although some theories develop the separate aspects of the interrelations of emotion and reason, actions and personality, much still must be done both on the theoretical and on the empirical levels.

In this work we have tried to implement emotional agents using two different approaches: appraisal theory with the PAD model and the central nervous system theory. We approach the concept of emotion from the physiological and psychological perspective, defining the personality of the agent and analyzing the different components of agent behaviors. We have simulated a kind of homogeneous and non-homogeneous society with different personalities and analyzed their group and individual performances.

We can conclude that our approach produce very good results showing the dependence between two different layers (physiological and psychological) which where implemented independently. Hence, as it already has been proved theoretically from psychological perspective, which define that our emotional process are dependent on our temperamental type, we could state that our architecture is consistent and show the same interaction between two layers. This let us a large room for future improvement and research on this area.

In order to improve our model we want to implement sub-layers for modular emotional evaluation of the external events. Also we want to study different search algorithms applied to our system to evaluate the impact of emotions and temperament on search strategies. Other possible development is the introduction of visual emotional feedback using the face expressions such as proposed by the Russel [19]. Also we are aiming at the introduction of additional objects in the simulation environment with different degree of thread/satisfaction and definition of the universal conditions for appraisal banks possible to use for different emotional appraisal systems.

Other evaluation strategies will be performed, such as comparison of team performance with different number of agents and pair/impair number of agents in the team.

\section{REFERENCES}

[1]Hille, K., Synthesizing Emotional Behavior in a Simple Animated Character, Artificial Life, 2001, Vol. 7, No. 3, pp. 303-313.
[2]Sloman, A., Croucher, M., Why Robots will have Emotions, IJCAI, 1981.

[3]Sarmento, L., An Emotional-Based Agent Architecture, Msc Thesis, Faculty of Science of Porto University, Portugal, 2004

[4]Picard, R. W., Affective Computing, MIT Press, 1997

[5]Velásquez, J., Modeling emotion-based decision-making. In Dolores Cañanero, editor, Proceedings of the 1998 AAAI Fall Symposium Emotional and Intelligent: The Tangled Knot of Cognition, pages 164-169, Orlando, FL, USA, 1998. http://www.ai.mit.edu/people/jvelas/papers/VelasquezFS98.ps.

[6]Cañamero, L., Designing emotions for activity selection. Technical Report TR - DAIMI PB 546, Univesity of Arhaus, 2000. http://citeseer.nj.nec.com/384344.html.

[7] Cañamero, L., A hormonal model of emotions for behavior control. Presented as poster at the Fourth European Conference on Artificial Life (ECAL 97), Brighton, UK, 1997.

http://citeseer.nj.nec.com/canamero97hormonal.html.

[8]Cañamero, L., Issues in the design of emotional agents. In AAAI Fall Symposium on Emotional and Intelligent: The tangled knot of cognition, pages 49-54, Menlo Park, CA, 1998. http://citeseer.nj.nec.com/437878.html.

[9]Frijda, N. H., The Emotions. Cambridge University Press, 1986.

[10]Frijda, N. H., Emotions are functional, most of the time. In Paul Ekma and Richard The Nature of Emotion Fundamental Questions. Oxford University Press, 1994.

[11]Gebhard, P., ALMA - A Layered Model of Affect, Proceedings of the Fourth International Joint Conference on Autonomous Agents and Multiagent Systems (AAMAS'05), 29-36, Utrecht, 2005

[12]Pereira, D., Oliveira, E., Moreira, N., Sarmento, L., "Towards an Architecture for Emotional BDI Agents", In IEEE Proceedings of EPIA, Covilhã, December 2005

[13]Dias, J., Paiva, A., "Feeling and Reasoning: a Computational Model for Emotional Characters", in EPIA Affective Computing Workshop, Covilhã, Springer, 2005

[14] Prada, R., Teaming Up Humans and Synthetic Characters - PhD Thesis, UTL-IST, Lisboa, Dezembro de 2005.

[15]Prada, R., Paiva, A.: Believable groups of synthetic characters. AAMAS2005: 37-43 ACM-Press

[16]Bartneck, C., How convincing is Mr. Data's smile: Affective expressions of machines. User Modeling and User-Adapted Interaction, 11, pp. 279-295. 2001

[17]Ortony, A., Clore, G. L., Collins, A., "The Cognitive Structure of Emotions." Cambridge University Press, Cambridge, UK, 1988.

[18]Petta, P., "The role of emotions in tractable architectures for situated cognizers." In Robert Trappl, Paolo Petta, and Sabine Payr, editors, Emotion in Humans and Artifacts. MIT Press, Cambridge, MA, 2002.

[19]Russel, J.A., A Circumplex Model of Affect. Journal of Personality and Social Psychology, 1980, No. 39, pp. 1161-1178.

[20]Mehrabian, A. Pleasure-Arousal-Dominance: A General Framework for Describing and Measuring Individual Differences in Temperament. Current Psychology: 
Developmental, Learning, Personality, Social, Winter, 1996, Vol. 14, No. 4, 261-292.

[21]Mehrabian, A., Basic Dimensions for a General Psychological Theory, Cambridge: OG\&H Publishers, 1980.

[22]Minsky, M., The Society of Mind, First Touchstone Edition, 1988.

[23]Darwin, C., "The Expression of the Emotions in Man and Animals", 1872

[24]Izard, Carroll E., Human Emotions. Plenum Press, New York, 1977.

[25]Izard, C. E., Libero, D. Z., Putnam, P., \& Haynes, O. M., "Stability of emotion experiences and their relations to traits of personality." Journal of Personality and Social Psychology, 64, 847-860, 1993

[26]Eysenck, H. J. , The Scientific Study of Personality, L., 1952

[27]Damásio, A. R., Descartes's Error: Emotion, Reason and the Human Brain. Gosset/Putman, New York, 1994.

[28]Павлов, И.П., Общие типы высшей нервной деятельности животных и человека, Москва, 1927/ Pavlov, I. P., General Types of Superior Nervous System in Animal and Man, Moscow, 1927

[29]Gadanho, S. C., Emotional and cognitive adaptation in real environments. In the symposium ACE'2002 of the 16th European Meeting on Cybernetics and Systems Research, Vienna, Austria, 2002.

[30]Gadanho, S. C., Hallam, J. Emotion triggered learning for autonomous robots. In Dolores Cañamero, Chisato Numaoka, and Paollo Petta, editors, SAB '98 Workshop on Grounding Emotions in Adaptive Systems, pages 31-36, August 1998.

[31]James, W., "What is an emotion?", Mind, 9(34):188-205, 1884.

[32]Gratch, J., Mao, W., Marsella, S., "Modeling Social Emotions and Social Attributions", Cognition and MultiAgent Interaction, Cambridge University Press, pp. 219251,2005

[33]Broekens, J., DeGroot, D., Formalizing Cognitive Appraisal: From Theory to Computation, Proceedings of the 18th European Meeting on Cybernetics and Systems Research (EMCSR 2006, Vienna, Austria) (pp. 595-600), ASCS: Vienna, 2006

[34]Lau, N., Pereira, A., Melo, A., Neves, A., Figueiredo, J., Ciber-Rato: Um Ambiente de Simulação de Robots Móveis e Autónomos, Revista do DETUA / Ciber-Mouse: A Simulation Environment for Mobile and Autonomous Robots, DETUA Journal, September, 2002, Vol. 3, No. 7, pp. 647-650.

[35]Lau, N. Manual do Simulador Ciber-Rato./ Manual for Ciber-Mouse Simulator, Aveiro University, Portugal, 2001

[36]RoboCup Official Site, http://www.robocup.org
[37]Павлов И. П. Полное собрание сочинений. Изд. 2-е. Т. 3 - 4. М.; Л., 1951.

[38]Mehrabian, A., Analysis of the Big-five Personality Factors in Terms of the PAD Temperamental Model. Australian Journal of Psychology, 1996, Vol. 48, No. 2, pp. 86-92.

[39]Barteneva, D., Lau, N., Reis, L. P., "Implementation of Emotional Behaviors in Multi-Agent System using Fuzzy Logic and Temperamental Decision Mechanism", In Proceedings of the Fourth European Workshop on MultiAgent Systems, pp. 5-11, Lisbon, 2006

\section{AUTHOR BIOGRAPHIES}

DARIA BARTENEVA was born in Moscow, Russian Federation and obtained a BSc degree in Applied Mathematics and Computer Science in Aveiro University and a MSc in Artificial Intelligence and Expert Systems in the University of Porto. After graduation, she worked 5 years in different software development companies focusing her attention in Business Intelligence. Since 2005 she is dedicated to research in the field of Agent-Based Simulation systems and Emotion Programming. Her e-mail address is: daria.barteneva@gmail.com.

LUIS PAULO REIS was born in Porto, Portugal and have a $\mathrm{PhD}$ in Electrotechnical Engineering (Coordination in Multi-Agent Systems) in the University of Porto. He has been researching in the area of (MultiAgent) intelligent simulation for several years in different projects including FC Portugal simulated robotic soccer team - World and European champion of RoboCup in 2000 and 2006. His e-mail address is lpreis@fe.up.pt and his web-page can be found at http://www.fe.up.pt/ lpreis.

NUNO LAU Nuno Lau has finished an Electrical Engineering degree from the Oporto University in 1993. In 1994 he completed the Diplome D'Études Approfundies in Biomedical Engineering from the Université Claude Bernard-Lyon 1. He has obtained his Phd in Electrical Engineering in 2003 from the Aveiro University. He has been working in the Aveiro University since 1994, where he is now Auxiliar Professor. His main research interests are Robotics, Simulation, Artificial Intelligence and Computer Architecture. In the course of his research activities he participated in several robotic competitions, having, among others, won two first places in the RoboCup Simulation League World Championship. His e-mail address is lau@det.ua.pt 